\title{
Increased Responsiveness to Toll-Like Receptor 4 Stimulation in Peripheral Blood Mononuclear Cells from Patients with Recent Onset Rheumatoid Arthritis
}

\author{
M. L. Kowalski, ${ }^{1}$ A. Wolska, ${ }^{1}$ J. Grzegorczyk, ${ }^{2}$ J. Hilt, ${ }^{1}$ M. Jarzebska, ${ }^{1}$ M. Drobniewski, ${ }^{3}$ \\ M. Synder, ${ }^{3}$ and M. Kurowski ${ }^{1}$ \\ ${ }^{1}$ Department of Immunology, Rheumatology and Allergy, Chair of Immunology, Medical University of Lodz, \\ Pomorska 251, 92-213 Lodz, Poland \\ ${ }^{2}$ Department of Laboratory Medical Immunology, Medical University of Lodz, Pomorska 251, 92-213 Lodz, Poland \\ ${ }^{3}$ Department of Orthopedics and Pediatric Orthopedics, Medical University of Lodz, Drewnowska 75, 91-002 Lodz, Poland \\ Correspondence should be addressed to M. L. Kowalski, marek.kowalski@csk.umed.lodz.pl
}

Received 6 December 2007; Accepted 28 March 2008

Recommended by Donna-Marie McCafferty

\begin{abstract}
Background. Cell signaling via Toll-like receptors (TLRs) leads to synovial inflammation in rheumatoid arthritis (RA). We aimed to assess effects of TLR2 and TLR4 stimulation on proinflammatory cytokine production by peripheral blood mononuclear cells (PBMCs) from patients with recent-onset RA, osteoarthrosis (OA), and healthy control (HC). Methods. PBMCs were stimulated with LPS, biglycan and cytokine mix. Cytokines were analyzed in supernatants with ELISA. Expression of toll-like receptors mRNA in leukocytes was analyzed using real-time qPCR. Results. PBMCs from RA patients spontaneously produced less IL-6 and TNF $\alpha$ than cells from OA and HC subjects. LPS increased cytokines' production in all groups. In RA patients increase was dramatic (30 to 48 -fold and 17 to 31 -fold, for respective cytokines) compared to moderate (2 to 8 -fold) in other groups. LPS induced 15-HETE generation in PBMCs from RA (mean 251\%) and OA patients (mean 43\%), although only in OA group, the increase was significant. TLR2 and TLR4 gene expressions decreased in response to cytokine mix, while LPS enhanced TLR2 expression in HC and depressed TLR4 expression in OA patients. Conclusion. PBMCs from recent-onset RA patients are overresponsive to stimulation with bacterial lipopolysaccharide. TLR expression is differentially regulated in healthy and arthritic subjects.
\end{abstract}

Copyright (C) 2008 M. L. Kowalski et al. This is an open access article distributed under the Creative Commons Attribution License, which permits unrestricted use, distribution, and reproduction in any medium, provided the original work is properly cited.

\section{INTRODUCTION}

Rheumatoid arthritis (RA) is a complex disease of yet unknown pathogenesis. Several factors have been proposed as potential triggers of inflammatory response associated with RA rheumatoid arthritis, including microbes and their products $[1,2]$. Products of invading microbes may activate inflammatory cells via Toll-like receptors (TLRs), which leads to immune and inflammatory responses. TLRs activation has been linked to the pathogenesis of rheumatoid arthritis, and both TLR- 2 and TLR- 4 are potentially critical receptors in the initiation and perpetuation of the inflammatory cycle in arthritis [3]. It has been also demonstrated that endogenous TLR4 ligands (e.g., heat shock proteins and extra domain A fibronectin) are highly expressed in the joints of patients with RA [4-6]. Toll-like receptors are present on tissue synoviocytes but also on peripheral blood monocytes which are recruited to the site of inflammation and are involved in the pathogenesis of synovial inflammation [710]. Recent studies described higher expression of TLR4 in leucocytes from patients with ankylosing spondylitis and increased expression of TLR2 and TLR4 receptors in cartilage lesions occurring during OA suggesting that abnormal TLR signaling may also be involved in the pathogenesis of rheumatologic conditions other than rheumatoid arthritis $[11,12]$.

IL- 6 and TNF $\alpha$ as well as IL- 1 family cytokines and chemokines have been markedly elevated in synovial fluid and synovial membranes from patients with RA, but not in patients with OA [13-15]. Moreover, in sera of RA patients spontaneous IL-1, $-6,-8,-18$, and TNF $\alpha$ production are significantly higher than in healthy individuals and 
TABLE 1: Clinical characteristic of patients.

\begin{tabular}{lccc}
\hline & Rheumatoid arthritis & Osteoarthrosis & Healthy control \\
\hline Female/male & $6 / 1$ & $7 / 0$ & $6 / 1$ \\
Age in years (median; range) & $56(35-68)$ & $59(53-75)$ & $32(27-55)$ \\
aCCP in IU/mL (mean \pm SD) & $68,76 \pm 47,17$ & $4,02 \pm 5,79$ & Not done \\
CRP mg/l (mean \pm SD) & $12 \pm 6$ & $6 \pm 0$ & Not done \\
DAS28 (median; min-max) & $4,2(1,96-6,27)$ & n/a & n/a \\
\hline
\end{tabular}

anti-TNF $\alpha$ treatment decreases local and systemic expression of TLR2 and TLR4 receptors [16, 17].

Earlier studies documented that peripheral blood mononuclear cells from RA patients generate significantly more inflammatory cytokines and chemokines, although the difference between patients with new onset and established rheumatoid arthritis could not be clearly determined [1821].

We aimed to assess the effect of Toll-like receptors 2 and 4 stimulation on production of inflammatory cytokines and generation of 15-HETE by PBMCs from patients with newly diagnosed RA in comparison with patients with osteoarthrosis and healthy controls. In addition, we sought to determine in what way the stimulation of TLRs (exemplified by TLR4 stimulation in our experiments) on leucocytes' surface might affect expression of Toll-like receptors themselves on the mRNA level. Finally, we investigated the influence leucocytes' stimulation with mix of strong proinflammatory cytokines on expression of TLR2 and TLR4 at mRNA level.

\section{METHODS}

\subsection{Patients}

Twenty one subjects were recruited to the study, including 7 patients with rheumatoid arthritis (RA), 7 patients with osteoarthrosis (OA) and 7 healthy control (HC) subjects. $\mathrm{RA}$ and $\mathrm{OA}$ were diagnosed according to American College of Rheumatology guidelines [22]. Severity of rheumatoid arthritis was assessed employing the composite 28-joint disease activity score (DAS28). Although no gold standard for assessment of RA activity exists, the DAS28 score has been adopted by European rheumatologists as a daily practice tool $[23,24]$. DAS28 scoring provides a numeric index, in which a score $>5.1$ implies high-disease activity, a score $<3.2$ indicates low disease activity, and a score $<2.6$ indicates remission. Patients with RA were newly diagnosed and had not received disease-modifying antirheumatic drugs (DMARDs) before inclusion into the study and presented with moderate disease activity according to DAS28 (mean index $\pm \mathrm{SD} ; 4,31 \pm 1,32)$. Additional parameters used for clinical characterization of patients included anti-cyclic citrullinated peptide antibodies (aCCPs) as well as C-reactive protein (CRP) serum concentration measurements. Serum aCCP presence is a marker of early phase RA. They are more specific as a diagnostic tool than RF and are considered a good predictor of severe erosive disease [25]. CRP elevation is the most useful index of the acute phase response being specific, sensitive, and rising rapidly during 6 to 10 hours after the initiation of an inflammatory process [26].

The aCCPs were detected in all RA patients and in none of patients without RA. The concentration of C-reactive protein (CRP) in serum was increased in RA compared to OA patients. Control group consisted of young healthy volunteers. A clinical characteristic of patients is presented in Table 1.

All participants gave their written consent after being fully informed about the purpose of the study, which was previously approved by Local Bioethics Committee of the Medical University of Lodz.

\subsection{Purification of peripheral blood mononuclear cells}

Blood samples $(27 \mathrm{~mL}$ per patient) were collected by peripheral venipuncture. Peripheral blood mononuclear cells were purified by centrifugation on Histopaque-1077 (Sigma Aldrich, St. Louis, Mo, USA). Briefly, peripheral blood was diluted with phosphate buffered saline and carefully layered onto Histopaque-1077 and centrifuged at $400 \mathrm{~g}$ for 30 minutes at room temperature. The opaque interface was washed three times and finally resuspended at a density of $10^{6}$ cells $/ \mathrm{ml}$ in RPMI-1640 medium (Sigma Aldrich, St. Louis, Mo, USA) supplemented with 10\% heat inactivated Fetal Bovine Serum (Sigma-Aldrich, St. Louis, Mo, USA), antibiotic (penicillin, streptomycin), and antimycotic (amphothericin B) solution (Sigma Aldrich, St. Louis, Mo, USA).

\subsection{Cell stimulation}

PBMCs were incubated with LPS at a concentration of 1 , 10 , and $100 \mathrm{ng} / \mathrm{mL}$, biglycan (BGN) at concentrations of $0.1,1$, and $10 \mathrm{ng} / \mathrm{mL}$ and with cytokine mix (including $10 \mathrm{ng} / \mathrm{mL}$ of IL-1, $10 \mathrm{ng} / \mathrm{mL}$ IL-6, and $100 \mathrm{ng} / \mathrm{mL} \mathrm{TNF} \alpha$ ) for 24 hours. After centrifugation, supernatants were harvested and analyzed for IL- 6 or TNF $\alpha$ using ELISA kits (Bender MedSystems Inc., Burlingame, Calif, USA).

\subsection{RNA isolation and reverse transcription}

Total RNA was isolated from leukocytes using Total RNA Mini kits (A\&A Biotechnology, Gdynia, Poland) in accordance with manufacturer's instructions. Total RNAs were converted to complementary DNA (cDNA) by random priming with M-MLV reverse transcriptase (Promega, 
TABLE 2: Spontaneous and stimulated IL-6 production by peripheral blood mononuclear cells from patients with rheumatoid arthritis (RA), osteoarthrosis(OA), and healthy controls (HC); median values; $P<.05^{*}$ —significantly different from nonstimulated; \#—significant difference between $\mathrm{RA}$ and $\mathrm{HC}^{\wedge} \_$- significant difference between $\mathrm{RA}$ and $\mathrm{OA}$.

\begin{tabular}{lccccccc}
\hline & \multirow{2}{*}{ Nonstimulated } & \multicolumn{5}{c}{ Stimulus } \\
& & LPS 1 ng/mL & LPS 10 ng/mL & LPS 100 ng/mL BGN 0,1 ng/mL & BGN1\# ng/mL & BGN\#10 ng/mL \\
\hline Group of subjects & & \multicolumn{2}{c}{ concentration of IL-6 (ng/mL) } \\
\hline RA & $0,56 \#^{\wedge}$ & $22,87^{*}$ & $42,95^{* \wedge}$ & $46,72^{*}$ & $2,0^{\wedge}$ & $1,24 \#^{\wedge}$ \\
OA & 27,2 & $43,6^{*}$ & $88,47^{*}$ & $75,1^{*}$ & 22,6 & 33,01 & $2,55 \#^{\wedge}$ \\
HC & 25,45 & $86,46^{*}$ & 73,47 & $99,11^{*}$ & $21,15^{*}$ & 50,81 & 46,0 \\
\hline
\end{tabular}

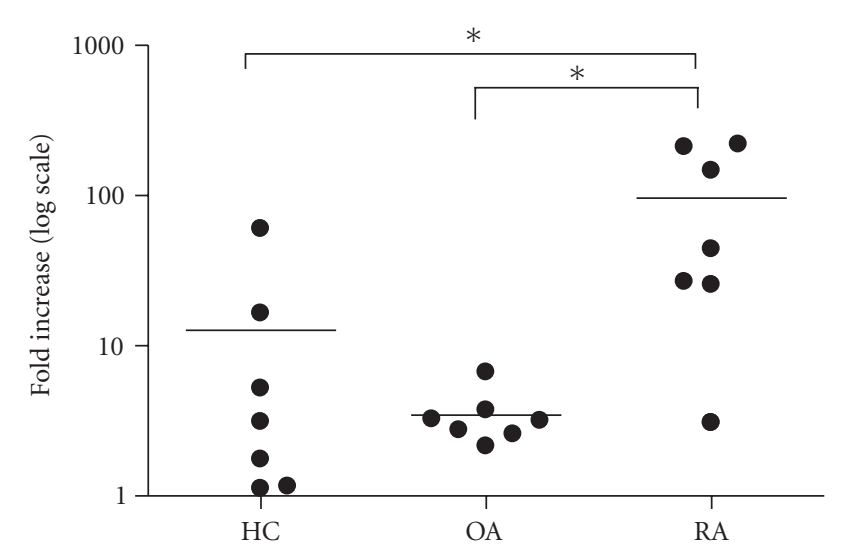

FIgURE 1: Individual changes in IL-6 concentration in the supernatants of human leucocytes culture after stimulation with LPS at $100 \mathrm{ng} / \mathrm{mL}$; $\log 10$ scale; HC-healthy controls, OA-osteoarthrosis, RA-rheumatoid arthritis; ${ }^{*} P<.03$, Wilcoxon's test.

Madison, Wis, USA). After reverse transcription, cDNA was stored at $-20^{\circ} \mathrm{C}$ for further analysis.

\subsection{Quantitative real-time PCR}

Quantitative real-time PCR was performed using ABI Prism 7000 Sequence Detection System (Applied Biosystems, Foster City, Calif, USA). We used iTaq SYBR Green Supermix With ROX (Bio-Rad Laboratories, Inc., Hercules, Calif, USA) as suggested by the manufacturer. In brief, reactions were carried out in $20 \mu \mathrm{l}$ containing $1 \mu \mathrm{l} \mathrm{cDNA}, 10 \mu \mathrm{l} 2 \times$ SYBR Green supermix, and $200 \mathrm{nM}$ of each specific primer. The cycling parameters were 3 minutes at $95^{\circ} \mathrm{C}$ followed by 45 cycles of denaturation at $95^{\circ} \mathrm{C}$ for 15 seconds and annealing/extension at $60^{\circ} \mathrm{C}$ for 45 seconds. For relative quantification, an $n-$ fold differential expression has been calculated using $2^{-\Delta \Delta \mathrm{Ct}}$ method. Amplification of each target gene (TLR2 and TLR4) was normalized to that of $\beta$-actin (housekeeping gene). Amplified products were checked for their correct size by means of agarose gel electrophoresis. Specific primers used for TLR2, TLR4, and $\beta$-actin amplification were described previously by Gutiérrez-Cañas et al. [27] and their sequences were as follows: TLR2 sense 5'GGA AGA ATC CTC CAA TCA GGC 3'; TLR2 antisense 5'CTT CTG TGA GCC CTG AGG GA 3'; TLR4 sense 5'AGC CAC GCA TTC ACA GGG $3^{\prime}$; TLR4 antisense 5'CAT GGC TGG GAT CAG AGT CC 3'; $\beta$-actin sense $5^{\prime}$ AGA AGG ATT CCT ATG TGG GCG $3^{\prime} ; \beta$ actin antisense $5^{\prime}$ CAT GTC GTC CCA GTT GGT GAC $3^{\prime}$.

\section{RESULTS}

\subsection{IL-6 production by PBMCs in response to stimulation with LPS and biglycan}

Nonstimulated PBMCs from RA patients demonstrated a significantly lower production of IL-6 as compared to OA patients (median value 48 times lower) and to control subjects (median value 45 times lower) (Table 2). Stimulation with LPS, an agonist for TLR4 receptors, resulted in significant increase in IL-6 production in all 3 groups. However, in cells from patients with RA, the increase was dramatic (median 30, 48, and 44 folds over baseline after 1,10 , and $100 \mathrm{ng} / \mathrm{mL}$ of LPS, resp.) as compared to only moderate ( 2 to 4 folds) increase observed in cells from patients with OA or healthy subjects (Figure 1).

Incubation of cells with biglycan, the agonist for TLR2 receptors, resulted in small and nonsignificant increase in IL6 production in both RA patients (after all biglycan concentrations) and AO patients (only after biglycan at $1 \mathrm{ng} / \mathrm{mL}$ ). In healthy subjects, insignificant increases were observed following 2 highest concentrations, and small decrease (22\%) was noticed after the lowest biglycan concentration.

\subsection{TNF $\alpha$ production by PBMCs in response to stimulation with LPS and biglycan}

Nonstimulated PBMCs from RA patients generated significantly less $\mathrm{TNF} \alpha$ as compared to OA patients (mean 12 times less) and control subjects (mean 10 times less) (Table 3). Incubation with LPS induced an increase in TNF$\alpha$ production in all 3 groups. However, similarly to IL-6, the increase in $\mathrm{TNF} \alpha$ production was significantly more intense after LPS at 10 and $100 \mathrm{ng} / \mathrm{mL}$ (resp., 31 and 29 folds over the baseline) as compared to that observed in cells from patients with OA (mean 3 to 8 folds increase for different LPS concentrations) or healthy subjects (mean 4- to 7-fold increase for different LPS concentrations) (Figure 2). Stimulation with biglycan induced a significant increase in TNF $\alpha$ production only in PBMCs from healthy subjects in response to the highest concentration.

\subsection{5-HETE generation by PBMCs in response to stimulation with LPS and biglycan}

15-HETE was generated by unstimulated PBMCs cells from both RA and OA patients in similar amounts. Stimulation with LPS increased 15-HETE generation in 5 RA patients 
TABLE 3: Spontaneous and stimulated TNF $\alpha$ production by peripheral blood mononuclear cells from patients with rheumatoid arthritis (RA), osteoarthrosis (OA), and healthy control (HC); $P<.05^{*}$ —significantly different from nonstimulated; \#-significant difference between $\mathrm{RA}$ and $\mathrm{HC}^{\wedge}$ — significant difference between $\mathrm{RA}$ and $\mathrm{OA}$.

\begin{tabular}{lccccccc}
\hline & Nonstimulated & LPS $1 \mathrm{ng} / \mathrm{mL}$ & LPS $10 \mathrm{ng} / \mathrm{mL}$ & LPS $100 \mathrm{ng} / \mathrm{mL}$ & BGN 0,1 ng/mL & BGN $1 \mathrm{ng} / \mathrm{mL}$ & BGN $10 \mathrm{ng} / \mathrm{mL}$ \\
\hline Group of subjects & & \multicolumn{7}{c}{ Concentration of TNF $\alpha(\mathrm{ng} / \mathrm{mL})$} \\
\hline RA & $0,05^{\wedge} \#$ & $0,72^{\wedge} \#$ & $2,02^{*}$ & $2,84^{*}$ & $0,1^{\wedge} \#$ & 0,26 \\
OA & 0,59 & $4,71^{*}$ & $2,48^{*}$ & $2,62^{*}$ & 0,84 & $0,07^{\wedge} \#$ \\
HC & 0,49 & $2,59^{*}$ & $1,98^{*}$ & $1,94^{*}$ & 0,63 & 0,45 & 0,71 \\
\hline
\end{tabular}

TABLE 4: Relative quantification of the TLR2 and TLR4 mRNA expression in PBMCs from patients with rheumatoid arthritis (RA), osteoarthrosis (OA), and healthy control (HC).

(a) Target gene expression is normalized to housekeeping gene expression and presented as $n$-fold of the expression in HC group $\left(2^{-\Delta \Delta C T}\right)$. * denotes significant difference in expression comparing with $\mathrm{HC}(P<$ $.03)$.

\begin{tabular}{cccc}
\hline & Nonstimulated & Cytokine mix & LPS \\
\hline TLR2 & & & \\
\hline HC & 1 & 1 & 1 \\
RA & 2.045 & 2.915 & 0.036 \\
OA & 1.218 & 1.66 & 0.074 \\
\hline TLR4 & & & \\
\hline HC & 1 & 1 & 1 \\
RA & $0.008^{*}$ & 0.225 & $0.0009^{*}$ \\
OA & $0.004^{*}$ & $0.044^{*}$ & $0.00002^{*}$ \\
\hline
\end{tabular}

(b) Target gene expression after stimulation with cytokine mix or LPS is normalized to housekeeping gene expression and presented as $n$-fold of the expression in non stimulated cells from patients from every group $\left(2^{-\Delta \Delta C T}\right)$. Significant differences in expression compared to nonstimulated cells are marked with ${ }^{*} P<0.02$; ${ }^{\#} P<0.01$.

\begin{tabular}{cccc}
\hline & Nonstimulated & Cytokine mix & LPS \\
\hline TLR2 & \multicolumn{3}{c}{} \\
\hline HC & 1 & 0.268 & $17.753^{*}$ \\
RA & 1 & 0.382 & 0.316 \\
OA & 1 & $0.365^{\#}$ & 1.071 \\
\hline TLR4 & & & \\
\hline HC & 1 & $0.00006^{*}$ & 0.1 \\
RA & 1 & 0.212 & 1.498 \\
OA & 1 & $0.093^{\#}$ & $0.092^{*}$ \\
\hline
\end{tabular}

(range $27-320 \%$ ) while decreased in 2 patients $(32 \%$ and $34 \%$, resp.). In OA patients, LPS induced a significant $(P<$ .005 ) increase in 15-HETE production (mean increase $43 \%$; range $20-175 \%$ ) (Figure 3 ). Incubation with biglycan did not affect 15-HETE generation.

\subsection{Effect of cytokines and LPS on TLR2 and TLR4 gene expression in PBMCs}

Expression of TLR2 mRNA in nonstimulated, cytokine mixstimulated, or LPS stimulated cells was similar in RA, OA and HC subjects (Table 4(a)). Mean expression of TLR-4

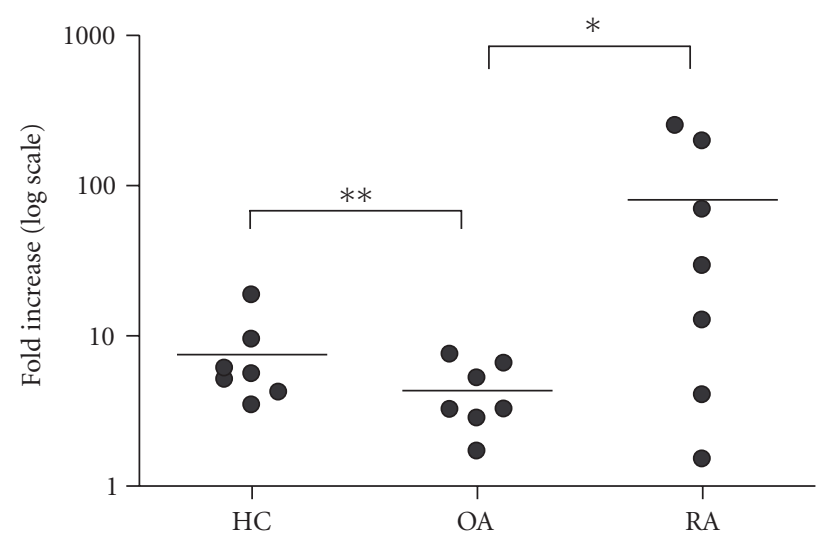

Figure 2: Individual changes in TNF $\alpha$ concentration in the supernatants of human leucocytes culture after stimulation with LPS $100 \mathrm{ng} / \mathrm{mL}$; $\log _{10}$ scale; HC-healthy controls; OA-osteoarthritis; RA-rheumatoid arthritis; ${ }^{*} p=.04 ;{ }^{* *} p=.027$.

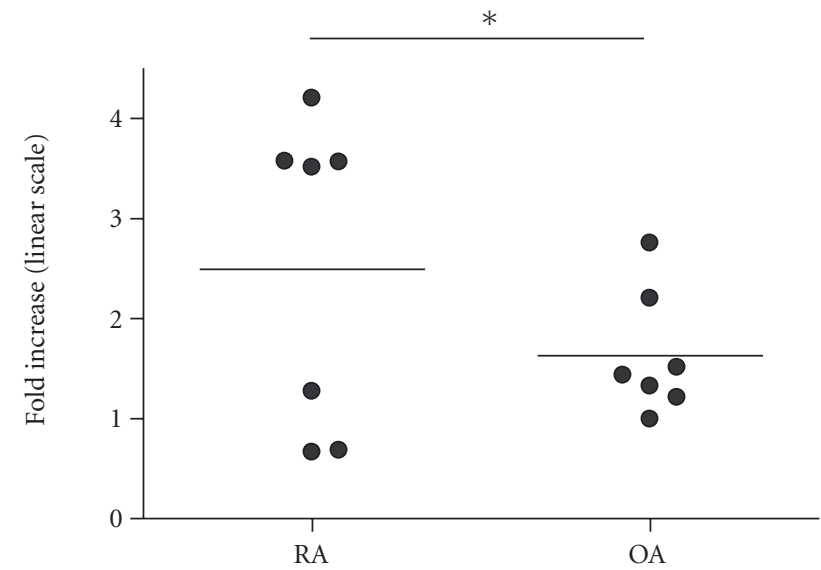

FIGURE 3: Changes in 15-HETE release into mononuclear cells supernatants after stimulation with $100 \mathrm{ng} / \mathrm{mL}$ LPS in individual patients OA-osteoarthritis; RA-rheumatoid arthritis; ${ }^{*} p<.01$.

mRNA in nonstimulated as well as in LPS or cytokine-mix stimulated cells was similar in patients with RA and OA, although in both groups, it was significantly lower than in cells from HC.

Incubation with cytokine mix tended to decrease both TLR2 and TLR4 expressions although the decrease was significant for both receptors in OA patients and for TLR4 in HC subjects (Table 4(b)). TLR2 gene expression was significantly increased by LPS in healthy controls, while significant 
suppression of TL4 mRNA expression was observed after LPS in cells from patients with OA.

\section{DISCUSSION}

This study was aimed at investigation of the significance of TLRs and their stimulation in contribution to development of a chronic inflammatory process present in patients with rheumatoid arthritis. We have demonstrated that peripheral blood mononuclear cells from patients with newly detected RA spontaneously generated significantly smaller amounts of interleukin- 6 and TNF $\alpha$ as compared to monocytes from OA patients or healthy subjects and that stimulation with LPS resulted in dramatically higher augmentation of cytokine production in cells from RA patients as compared to OA patients. Low-basal production of cytokines is an unexpected finding, since these two cytokines are considered to play a significant role in the pathogenesis of joint inflammation in RA; TNF $\alpha$ and IL- 6 may stimulate collagenase production, increase bone resorption and inhibit cartilage regeneration targeting fibroblasts, osteoclasts, and chondrocytes [28, 29]. Accordingly, previous studies demonstrated increased serum concentrations and enhanced generation of both cytokines by mononuclear cells from patients with RA [17-21]. Low baseline cytokine production in circulating mononuclear cells may be explained by the fact that we have studied patients with early detected RA; it is possible that at this stage of the disease, cells with high potential for cytokine production have been recruited to the site of inflammation (synovium) and only less active ones are available in the peripheral circulation. The most striking observation is a dramatic difference in response to stimulation with lipopolysaccharides between mononuclear cells from RA as compared to OA and healthy controls. Although in patients with OA and healthy controls LPS induced significant (2-7fold) increase in production of both cytokines, the increases in monocytes from RA patients were dramatic: 17 to 31 folds for TNF $\alpha$ and 30 to 48 folds for IL-6. These observations indicate that monocytes from patients with early detected $\mathrm{RA}$, in spite of having low-baseline production of cytokines demonstrate high potential for cytokine generation upon stimulation with LPS. LPS is thought to activate cells through specific TLR4 receptor which triggers a complex signaling cascade leading to release of inflammatory mediators potentially contributing to development of synovial inflammation. It has been previously demonstrated that TLR2 and TLR4 ligands enhance cytokine expression in synovial fluid macrophages from RA patients and induce catabolic responses in chondrocytes from OA patients [12, 30]. Our observation is in line with putative role of TLR4 receptors in the development of inflammatory responses in rheumatoid arthritis, suggesting that even in patients with newly detected and not yet pharmacologically treated RA, circulating inflammatory cells (monocytes) can be easily triggered via TLR4 stimulation to generate proinflammatory cytokines.

15-HETE is an arachidonic acid metabolite generated by reticulocyte-type B synoviocytes in human rheumatoid arthritis with potential modulatory effect on inflammation
$[31,32]$. We have demonstrated for the first time that stimulation of TLR4 but not TLR2 receptors increases generation of 15-HETE by mononuclear cells from both RA and OA patients. Although LPS consistently increases 15HETE generation in cells from 7 of 7 OA patients, in 4 of 7 patients with RA, the enhancement in 15-HETE generation by LPS was much higher. Further studies are necessary to elucidate the potential role of TLR4-triggered 15-HETE generation in the pathogenesis of RA and OA.

Higher responsiveness of monocytes from RA subjects to LPS as compared to cells from OA subjects and healthy controls could be explained by increased expression of TLR4 receptors on cell surface. Increased expression of Toll-like receptors on synoviocytes derived from the site of rheumatoid inflammation has been reported [33, 34]. However, information on TLRs expression on peripheral blood monocytes is less consistent and studies using either cytofluorometry to detect TLR2 and TLR4 protein or RTPCR to detect receptor transcript reported variable results $[29,30]$.

In this study, we used quantitative real-time PCR technique to asses TLR2 and TLR4 expressions in mononuclear cells. Expression of those 2 types of TLRs was investigated in nonstimulated cells as well as under stimulatory conditions. We have chosen LPS - a TLR4 agonist-and mix of potent proinflammatory cytokines as stimulants for this part of our experiments. Although the level of expression of TLR2 gene was not significantly different among three groups, expression of TLR4 mRNA was significantly decreased in cells from RA or OA patients as compared of healthy controls. However, these data have to be interpreted with caution since mRNA was isolated from total leukocyte population and its measurement might not reflect receptor expression in monocytes, which are primarily targeted by TLR agonists. Moreover, recent studies demonstrated dissociation of mRNA expression of Toll-like receptors from the modulation of TLR-mediated responses, suggesting that factors other than receptor expression may be responsible for increased responsiveness of RA monocytes to TLR ligands [26, 35]. RT-PCR technique allowed us to analyze TLR mRNA expression in response to stimulation with cytokine $\operatorname{mix}$ (IL1, TNF $\alpha$ and IL-6) and LPS. While cytokine mix tended to decrease Tolllike receptors gene expression in all groups studied, LPS had more variable effects: enhancement of TLR2 receptors was observed in healthy controls while significant depression of TLR4 expression was noticed in patients with osteoarthritis. These observations confirm that TLR agonist similarly to endogenous cytokines may modulate expression of Toll-like receptors on leukocytes and suggest that this modulation may vary in cells derived from patients with different form of rheumatic pathology or from healthy persons.

In conclusion, our study demonstrated a significant overresponsiveness of peripheral blood mononuclear cells from patients with recently diagnosed rheumatoid arthritis to stimulation with a bacterial product, lipopolysaccharide. Regulation of TLR expression by cytokine and TLR agonist may differ in healthy subjects and patients with arthritides. 


\section{ACKNOWLEDGMENT}

The study was supported by the research Grant no. 3 PO5B 12225 from the Polish Research Committee.

\section{REFERENCES}

[1] S. M. Behar and S. A. Porcelli, "Mechanisms of autoimmune disease induction: the role of the immune response to microbial pathogens," Arthritis \& Rheumatism, vol. 38, no. 4, pp. 458-476, 1995.

[2] A. Krause, T. Kamradt, and G. R. Burmester, "Potential infectious agents in the induction of arthritides," Current Opinion in Rheumatology, vol. 8, no. 3, pp. 203-209, 1996.

[3] T. R. D. J. Radstake, A. W. T. van Lieshout, P. L. C. M. van Riel, W. B. van den Berg, and G. J. Adema, "Dendritic cells, Fcy receptors, and Toll-like receptors: potential allies in the battle against rheumatoid arthritis," Annals of the Rheumatic Diseases, vol. 64, no. 11, pp. 1532-1538, 2005.

[4] J. Kriegsmann, A. Berndt, T. Hansen, et al., "Expression of fibronectin splice variants and oncofetal glycosylated fibronectin in the synovial membranes of patients with rheumatoid arthritis and osteoarthritis," Rheumatology International, vol. 24, no. 1, pp. 25-33, 2004.

[5] X. Chang, R. Yamada, A. Suzuki, Y. Kochi, T. Sawada, and K. Yamamoto, "Citrullination of fibronectin in rheumatoid arthritis synovial tissue," Rheumatology, vol. 44, no. 11, pp. 1374-1382, 2005.

[6] M. F. Roelofs, W. C. Boelens, L. A. B. Joosten, et al., "Identification of small heat shock protein B8 (HSP22) as a novel TLR4 ligand and potential involvement in the pathogenesis of rheumatoid arthritis," Journal of Immunology, vol. 176, no. 11, pp. 7021-7027, 2006.

[7] M. Iwahashi, M. Yamamura, T. Aita, et al., "Expression of Toll-like receptor 2 on CD16+ blood monocytes and synovial tissue macrophages in rheumatoid arthritis," Arthritis ¿ Rheumatism, vol. 50, no. 5, pp. 1457-1467, 2004.

[8] H. Hata, N. Sakaguchi, H. Yoshitomi, et al., "Distinct contribution of IL- 6 , TNF- $\alpha$, IL- 1 , and IL-10 to T cellmediated spontaneous autoimmune arthritis in mice," Journal of Clinical Investigation, vol. 114, no. 4, pp. 582-588, 2004.

[9] N. Kawanaka, M. Yamamura, T. Aita, et al., "CD14+,CD16+ blood monocytes and joint inflammation in rheumatoid arthritis," Arthritis \& Rheumatism, vol. 46, no. 10, pp. 25782586, 2002.

[10] G. R. Burmester, B. Stuhlmüller, G. Keyszer, and R. W. Kinne, "Mononuclear phagocytes and rheumatoid synovitis. Mastermind or workhorse in arthritis?" Arthritis \& Rheumatism, vol. 40, no. 1, pp. 5-18, 1997.

[11] Z.-X. Yang, Y. Liang, Y. Zhu, et al., "Increased expression of Toll-like receptor 4 in peripheral blood leucocytes and serum levels of some cytokines in patients with ankylosing spondylitis," Clinical \& Experimental Immunology, vol. 149, no. 1, pp. 48-55, 2007.

[12] H. A. Kim, M.-L. Cho, H. Y. Choi, et al., "The catabolic pathway mediated by Toll-like receptors in human osteoarthritic chondrocytes," Arthritis \& Rheumatism, vol. 54, no. 7, pp. 2152-2163, 2006.

[13] P. A. Guerne, B. L. Zuraw, J. H. Vaughan, D. A. Carson, and M. Lotz, "Synovium as a source of interleukin 6 in vitro. Contribution to local and systemic manifestations of arthritis," Journal of Clinical Investigation, vol. 83, no. 2, pp. 585-592, 1989.
[14] H. E. Barksby, S. R. Lea, P. M. Preshaw, and J. J. Taylor, "The expanding family of interleukin-1 cytokines and their role in destructive inflammatory disorders," Clinical \& Experimental Immunology, vol. 149, no. 2, pp. 217-225, 2007.

[15] J. Stanczyk, M. L. Kowalski, J. Grzegorczyk, et al., "RANTES and chemotactic activity in synovial fluids from patients with rheumatoid arthritis and osteoarthritis," Mediators of Inflammation, vol. 2005, no. 6, pp. 343-348, 2005.

[16] L. De Rycke, B. Vandooren, E. Kruithof, F. De Keyser, E. M. Veys, and D. Baeten, "Tumor necrosis factor $\alpha$ blockade treatment down-modulates the increased systemic and local expression of Toll-like receptor 2 and Toll-like receptor 4 in spondylarthropathy," Arthritis \& Rheumatism, vol. 52, no. 7, pp. 2146-2158, 2005.

[17] S. P. Paramalingam, J. Thumboo, S. Vasoo, S. T. Thio, C. Tse, and K.-Y. Fong, "In vivo pro- and anti-inflammatory cytokines in normal and patients with rheumatoid arthritis," Annals of the Academy of Medicine Singapore, vol. 36, no. 2, pp. 96-99, 2007.

[18] J. Hovdenes, T. K. Kvien, and A. B. Hovdenes, "IL-6 in synovial fluids, plasma and supernatants from cultured cells of patients with rheumatoid arthritis and other inflammatory arthritides," Scandinavian Journal of Rheumatology, vol. 19, no. 3, pp. 177-182, 1990.

[19] F. Lioté, B. Boval-Boizard, D. Weill, D. Kuntz, and J.-L. Wautier, "Blood monocyte activation in rheumatoid arthritis: increased monocyte adhesiveness, integrin expression, and cytokine release," Clinical \& Experimental Immunology, vol. 106, no. 1, pp. 13-19, 1996.

[20] K. S. Kanik, E. Hagiwara, C. H. Yarboro, H. R. Schumacher, R. L. Wilder, and D. M. Klinman, "Distinct patterns of cytokine secretion characterize new onset synovitis versus chronic rheumatoid arthritis," Journal of Rheumatology, vol. 25, no. 1, pp. 16-22, 1998.

[21] M. Vázquez-Del Mercado, V. Delgado-Rizo, J. F. MuñozValle, J. Orozco-Alcalá, H. D. Volk, and J. ArmendárizBorunda, "Expression of interleukin-1 beta, tumor necrosis factor alpha, interleukins- $6,-10$ and -4 , and metalloproteases by freshly isolated mononuclear cells from early never-treated and non-acute treated rheumatoid arthritis patients," Clinical \& Experimental Rheumatology, vol. 17, no. 5, pp. 575-583, 1999.

[22] American College of Rheumatology Subcommittee on Rheumatoid Arthritis Guidelines, "Guidelines for the management of rheumatoid arthritis: 2002 Update," Arthritis \& Rheumatism, vol. 46, no. 2, pp. 328-346, 2002.

[23] M. L. L. Prevoo, M. A. van't Hof, H. H. Kuper, M. A. van Leeuwen, L. B. A. van De Putte, and P. L. C. M. van Riel, "Modified disease activity scores that include twenty-eightjoint counts: development and validation in a prospective longitudinal study of patients with rheumatoid arthritis," Arthritis \& Rheumatism, vol. 38, no. 1, pp. 44-48, 1995.

[24] B. Hameed, J. Pilcher, C. Heron, and P. D. W. Kiely, "The relation between composite ultrasound measures and the DAS28 score, its components and acute phase markers in adult RA," Rheumatology, vol. 47, no. 4, pp. 476-480, 2008.

[25] K. Nishimura, D. Sugiyama, Y. Kogata, et al., "Meta-analysis: diagnostic accuracy of anti-cyclic citrullinated peptide antibody and rheumatoid factor for rheumatoid arthritis," Annals of Internal Medicine, vol. 146, no. 11, pp. 797-808, 2007.

[26] E. R. Banks, J. T. Whicher, D. Thompson, and H. A. Bird, "Acute phase response," in Oxford Textbook of Rheumatology, 
P. J. Maddison, D. A. Isenberg, P. Woo, and D. N. Glass, Eds., vol. 1, pp. 623-631, Oxford University Press, Oxford, UK, 2nd edition, 1998.

[27] I. Gutiérrez-Cañas, Y. Juarranz, B. Santiago, et al., "VIP downregulates TLR4 expression and TLR4-mediated chemokine production in human rheumatoid synovial fibroblasts," Rheumatology, vol. 45, no. 5, pp. 527-532, 2006.

[28] J.-M. Dayer, B. Beutler, and A. Cerami, "Cachectin/tumor necrosis factor stimulates collagenase and prostaglandin $\mathrm{E}_{2}$ production by human synovial cells and dermal fibroblasts," Journal of Experimental Medicine, vol. 162, no. 6, pp. 21632168, 1985.

[29] J. Saklatvala, "Tumour necrosis factor $\alpha$ stimulates resorption and inhibits synthesis of proteoglycan in cartilage," Nature, vol. 322, no. 6079, pp. 547-549, 1986.

[30] Q. Huang, Y. Ma, A. Adebayo, and R. M. Pope, "Increased macrophage activation mediated through Toll-like receptors in rheumatoid arthritis," Arthritis \& Rheumatism, vol. 56, no. 7, pp. 2192-2201, 2007.

[31] B. Liagre, P. Vergne, M. Rigaud, and J.-L. Beneytout, "Arachidonate 15-lipoxygenase of reticulocyte-type in human rheumatoid arthritis type B synoviocytes and modulation of its activity by proinflammatory cytokines," Journal of Rheumatology, vol. 26, no. 5, pp. 1044-1051, 1999.

[32] B. Deleuran, L. Iversen, M. Kristensen, et al., "Interleukin-8 secretion and 15-lipoxygenase activity in rheumatoid arthritis: in vitro anti-inflammatory effects by interleukin- 4 and interleukin-10, but not by interleukin-1 receptor antagonist protein," British Journal of Rheumatology, vol. 33, no. 6, pp. 520-525, 1994.

[33] R. Seibl, T. Birchler, S. Loeliger, et al., "Expression and regulation of Toll-like receptor 2 in rheumatoid arthritis synovium," American Journal of Pathology, vol. 162, no. 4, pp. 1221-1227, 2003.

[34] T. R. D. J. Radstake, M. F. Roelofs, Y. M. Jenniskens, et al., "Expression of Toll-like receptors 2 and 4 in rheumatoid synovial tissue and regulation by proinflammatory cytokines interleukin-12 and interleukin-18 via interferon- $\gamma$," Arthritis \& Rheumatism, vol. 50, no. 12, pp. 3856-3865, 2004.

[35] M. Franchini, M. Schweizer, P. Mätzener, et al., "Evidence for dissociation of TLR mRNA expression and TLR agonistmediated functions in bovine macrophages," Veterinary Immunology and Immunopathology, vol. 110, no. 1-2, pp. 3749, 2006. 


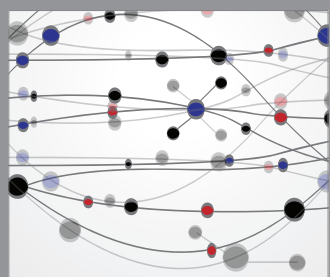

The Scientific World Journal
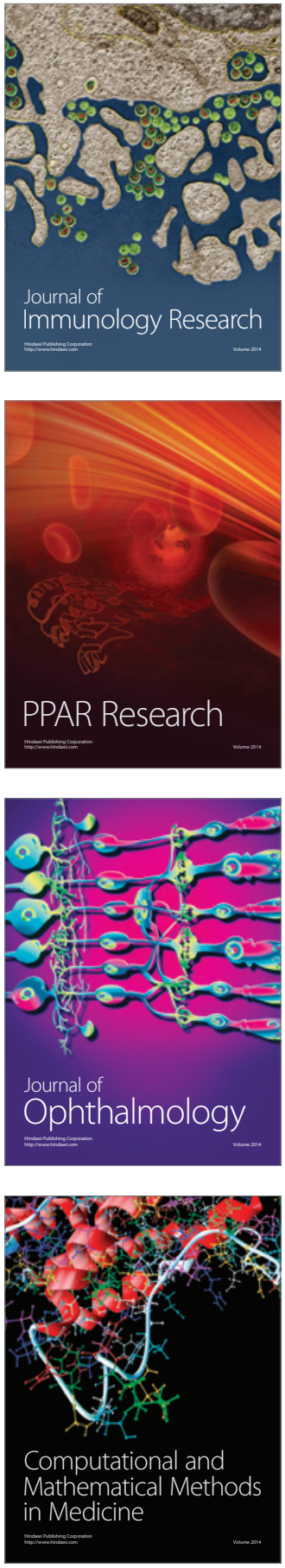

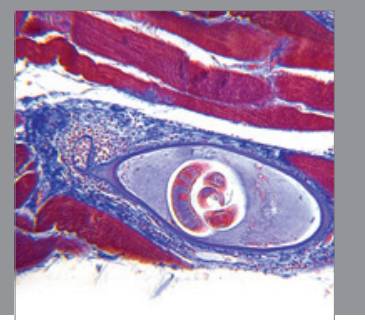

Gastroenterology

Research and Practice
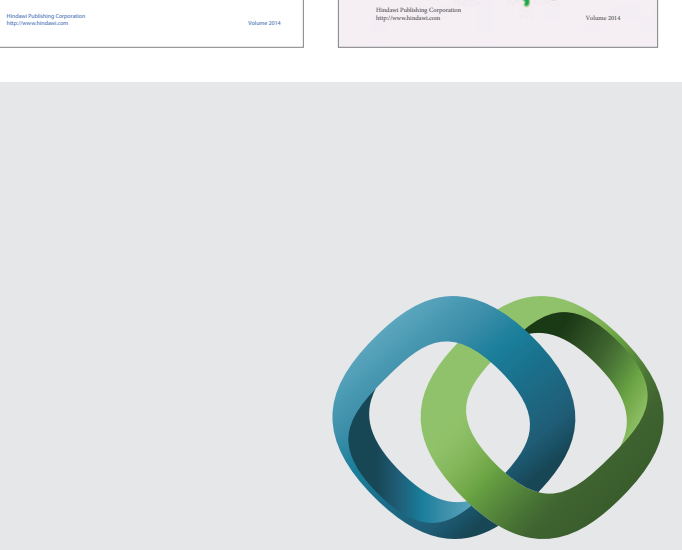

\section{Hindawi}

Submit your manuscripts at

http://www.hindawi.com
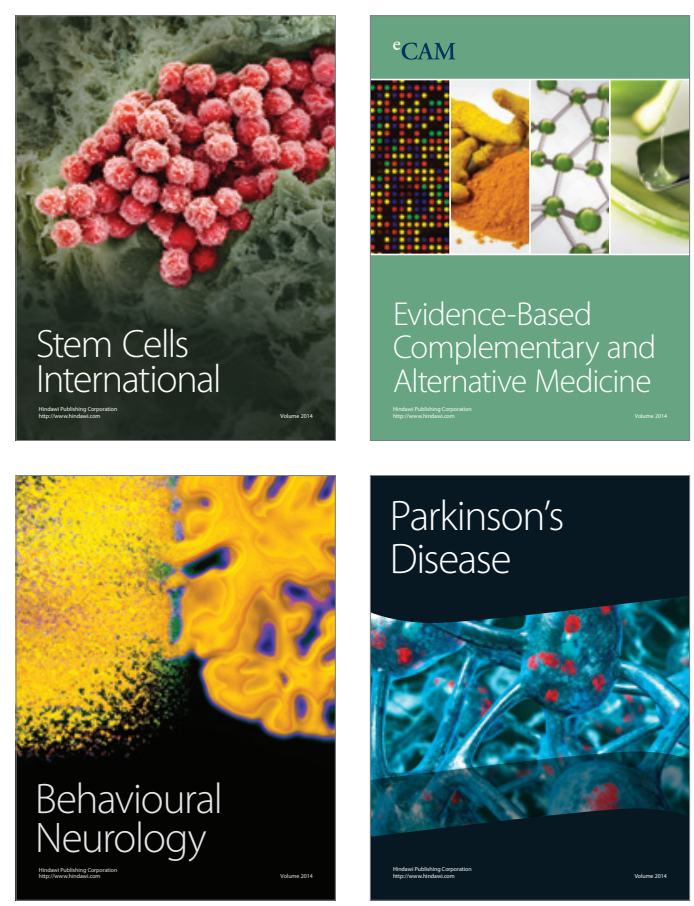

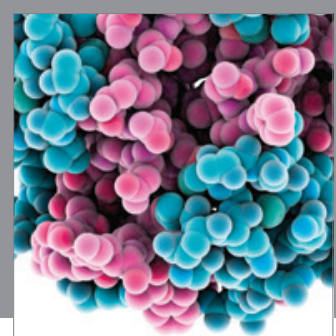

Journal of
Diabetes Research

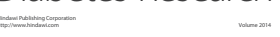

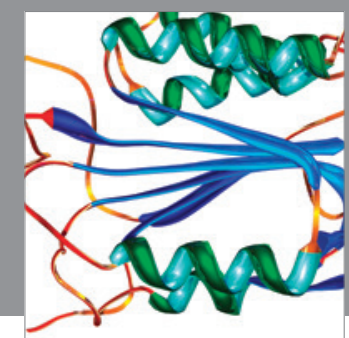

Disease Markers
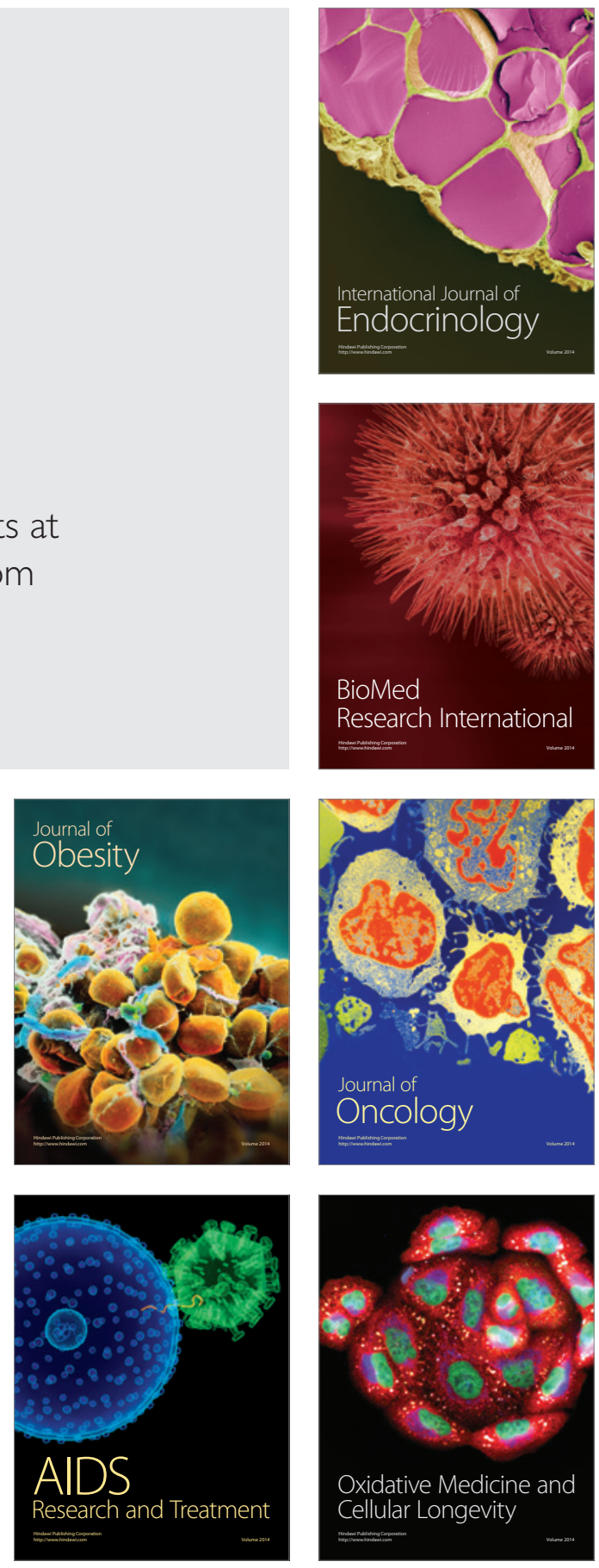